\title{
Overview of Entrepreneurial Failure: From an Attributional Perspective
}

\author{
Jing Li ${ }^{1}$, Jiangyu Huang ${ }^{2}$, , Jianhong $\mathrm{Li}^{1}$ \\ ${ }^{1}$ Faculty of Management and Economics, Kunming University of Science and Technology, Kunming, China \\ ${ }^{2}$ College of Big Data Application and Economics, Guizhou University of Finance and Economics, Guiyang, China
}

Email address:

1136591236@qq.com (Jiangyu Huang)

${ }^{*}$ Corresponding author

\section{To cite this article:}

Jing Li, Jiangyu Huang, Jianhong Li. Overview of Entrepreneurial Failure: From an Attributional Perspective. Journal of Investment and Management. Vol. 10, No. 1, 2021, pp. 1-7. doi: 10.11648/j.jim.20211001.11

Received: January 11, 2021; Accepted: January 20, 2021; Published: January 25, 2021

\begin{abstract}
Entrepreneurial failure is a hot topic in entrepreneurship research. Existing literature on entrepreneurial failure mainly focuses on the definition of entrepreneurial failure, the analysis of the causes of entrepreneurial failure, the different attributions of failure caused by different stakeholders due to cognitive biases, and the different reentrepreneurial actions caused by these differences in attributions. Based on the above literature and attribution theory, this paper proposes that future research should explore whether differences in gender, experience background (such as educational experience, etc.) and task type affect the attribution of entrepreneurial failure, as well as the mechanism by which they influence the attribution. The failure of enterprise entrepreneurship affects the healthy and sustainable development of the economy. Based on attribution reasons, the influencing factors of entrepreneurship failure are discussed, which provides useful evidence for government policy formulation. This Attribution theory points out that the diversity of individual attributions in different situations is not only due to the complexity of individual perception and motivation, but also due to the diversity of tasks. By comparing the causes of entrepreneurial failure and the attribution theory in previous entrepreneurial failure literatures, we propose three possible research directions in the future. Studies should make an in-depth study of entrepreneurs' perceptions of failure and the impact of these perceptions on learning.
\end{abstract}

Keywords: Entrepreneurial Failure, The Attribution Theory, Self-serving Bias, Serial Entrepreneurship

\section{Introduction of Entrepreneurial Failure}

Generally, failure refers to a condition in which the desired goal is not achieved [1]. Failure can be divided into different types according to its content, including project failure, product failure and personal failure, etc. [2-4]. This paper mainly focuses on the failure at the enterprise level, especially the failure of entrepreneurial enterprises.

In fact, most of the existing researches in the field of entrepreneurship equate the failure of start-ups with the failure of enterprises, but the definition of enterprise failure in the field of entrepreneurship specifically refers to new ventures, rather than mature enterprises in general. For example, the definition of Ucbasaran and his colleagues directly limits the action of bankruptcy or termination of business to the entrepreneurial enterprise $[5,6]$. Existing studies on entrepreneurship usually equate entrepreneurial failure with business failure of a new venture. The business failure or entrepreneurial failure of a new venture refers to the termination of the company due to its actual performance failing to achieve its goals [7, 8]. More specifically, from the perspective of financial, a company fails when its earnings decline or/and costs rise to the extent that the company is insolvent, unable to attract new borrowing or equity financing, and subsequently unable to continue operating under its current ownership and management [9].

Liao and his colleagues (2008) 's research only focuses on nascent entrepreneurs and defines the failure of the nascent entrepreneurial activity as the termination of its entrepreneurial activity [10]. Cope (2011) believes that entrepreneurial failure means that the company fails to reach its goal and meet the expectations of major shareholders, and 
therefore terminates [11]. Ucbasaran and his colleagues (2013) suggest that entrepreneurs stop participating in venture capital based on economic criteria as a criterion for failure. Business failure is clearly defined as the cessation of participation in entrepreneurship due to the failure to reach the minimum economic survival threshold set by entrepreneurs (or founders) [12]. In contrast, Mantere and his colleagues (2013) believe that failure does not necessarily require entrepreneurs to quit completely, nor does it necessarily require enterprises to terminate completely [13]. As long as performance deviates from expected results and questions the prevailing belief of entrepreneurs, such deviation should be considered a failure. In addition, some researchers argue that entrepreneurial failure is a phenomenon that can take many different forms. For example, Singh and his colleagues (2007) pointed out that entrepreneurial failure should include at least two factors, one is economic factors such as bankruptcy or liquidation, and the other is related to entrepreneurs [14]. In other words, entrepreneurial failure involves not only failures at the enterprise level, but also failures at the individual level [15]. It should be noted that in defining the failure of enterprise, it is critical to distinguish between failure and active company closures [16], which may include voluntary termination for reasons such as retirement or pursuing other more profitable or interesting new ventures [17], and these closures are often seen as active exits rather than failures [18].

As can be seen from the above definition, the dimensions of entrepreneurial failure are relatively vague. Some are measured from the perspective of personal failure of entrepreneurs, some are defined from the perspective of corporate failure, and some combine the two to illustrate entrepreneurial failure. As entrepreneurs are the most critical human resources in new ventures [19], they are both owners and managers, so it is difficult to separate entrepreneurs from their established companies. Therefore, entrepreneurial failure should include both the individual failure of entrepreneurs and the failure of their founding enterprises [20].

\section{Reasons for Entrepreneurial Failure}

There are many factors that lead to the failure of entrepreneurial activities. In the past studies, a large number of researchers have investigated the influence of different factors on the failure of entrepreneurial activities, which can be summarized into three levels: entrepreneur, enterprise and environment. In general, the entrepreneur level mainly refers to factors related to the individual entrepreneur, including management ability, socially constructed confidence, comparative optimism, gender, and so on. Management ability mainly refers to the entrepreneur's ability to make detailed long-term strategic planning, reasonably allocate resources, and lead the company to adapt to changing circumstances [21, 22]. Generally speaking, if entrepreneurs fail to formulate detailed long-term strategic plans, they just passively respond to external changes, which will make enterprises unable to compete in the changed environment and lead to entrepreneurial failure [21]. Socially constructed confidence refers to that entrepreneurs often overestimate the wealth they will gain from their new ventures. Entrepreneurs who have greater socially constructed confidence tend to underestimate the level of competition risk in the market, overestimate personal skills that can overcome the uncertainty, and ability to benefit from the existing resources. So they tend to make resource allocation decisions that almost exhaust the success opportunities of starting a new venture, or they are not adequately prepared for entrepreneurship, which increases the risk of failure [22]; Comparative optimism refers to the tendency of people to believe that they are less likely to experience negative events than others and are more likely to experience positive ones [23]. Comparative optimism may be necessary for starting a business, but it can also lead to entrepreneurial failure. More optimistic may cause entrepreneurs to set up enterprises under the circumstance of insufficient capital, while enterprises with insufficient capital are more likely to close [23]. Finally, women are more risk-averse than men, pay less attention to capital gains, engage more in industries with a high failure rate such as service or retail [24], and have less time to invest in enterprises due to multiple demands on women's time, which may lead to a higher failure rate for women than for men.

Factors at the enterprise level mainly include financial capital, product, distribution and sales strategy, team, etc. Because financial capital can be converted into other forms of resources, it becomes the most basic resource and the basis of other resources. However, it is very difficult for start-ups to acquire equity debt and equity financing [25], and insufficient initial capitalization will limit the development of enterprises and lead to their failure. Bruno and Leidecker (1988) compared the reasons for the failure of American start-ups in the 1860s and 1880s and found that in the early stage of product development, if the time and budget allocation of product design could not be met, thus affecting the timing of product entering the market, the failure of start-ups would result [26]. However, distribution and sales channels cannot match the type of products and the type of target consumers, which will have a negative impact on sales and lead to business failure. Team learning ability and cooperation efficiency will also influence the success or failure of an enterprise [26].

Environmental factors mainly include geographical location, labor cost, political and economic environment, social/cultural factors. Many studies have found that rural areas have economic disadvantages compared with urban areas, such as lower levels of economic development and limited job opportunities. For example, there are few banks in rural areas and access to finance in rural areas is difficult due to risks, financing necessities and regional biases. Moreover, compared with large cities, small cities lack professional services and have smaller markets [25]. All these disadvantages bring difficulties and challenges to local enterprises, leading to a higher failure rate; However, the high labor cost in urban areas will increase the burden on enterprises [27] and become an important factor leading to entrepreneurial failure. If the political and economic 
environment, such as laws and regulations, the level of economic development, and economic policies, does not support the development of entrepreneurship, these policies will further affect the availability of finance, education and training in the region, and the survival and development of enterprises will be difficult and the possibility of failure will increase [28]. Culture is generally defined as a collection of values, attitudes and meanings gradually formed and acquired in history by members of a given community, which influences both material and non-material lifestyles, including the development of enterprises [28]. If the community has a negative attitude towards enterprise development, low tolerance for failure, and does not recognize entrepreneurship as a way of life, it will affect the availability of social capital of the enterprise [29], affect the reputation of the entrepreneur [28], and thus lead to the failure of entrepreneurship.

Moreover, a number of studies have begun to take a holistic view of why startups fail. For example, Dipietro \& Sawhney (1977) pointed out that the internal management effectiveness and the external economic environment jointly determined the failure rate of small enterprises [30]. The research of Theng \& Boon (1996) shows that internal factors are more likely to cause SMEs to fail than external factors, among which the most important factor is the shortsightedness of the future and lack of relevant knowledge [31]. The study of Venkataraman and his colleagues (1990) highlighted the interaction between the liabilities of newness and smallness and the variability of external environment as the main cause of entrepreneurial failure [32].

\section{Entrepreneurial Failure and Attribution}

"There are a hundred reasons for success and a thousand reasons for failure" [33]. The reasons for business failure are diverse and will change with the change of the situation. However, the previous studies did not answer the question of why different subjects would give different explanations for the causes of failure, and there was no more general theoretical analysis framework for entrepreneurial failure. In recent years, scholars have begun to apply the attribution theory to explain the process of people's attribution of their failure [33]. Attribution is the mechanism that people use to explain their own behaviors, other people's actions, and events in the world [34], and the inevitable result of attribution is sensemaking -- the process that people attach meaning to ongoing events. In other words, people create a perceptual path map of cause and effect through attribution of events, individuals, or results to obtain a plausible result and provide a general background through which the result looks clear or at least more believable [35]. The rational reasons of entrepreneurial failure can be obtained through attribution

Entrepreneurial failure is an emergent event, and the attribution of failure is usually affected by the individual's cognition and attitude as well as the external environment. As to individual factors, when it comes to determining the cause of a poor performance or failure, the entrepreneur may try to hide his or her decision-making mistakes by attributing the cause of the failure to external factors rather than the internal ones, resulting in self-serving attribution error. Franco and Haase (2010) explored the attribution of failure through the personal entrepreneurship stories of 8 Portuguese SMEs, and found that although external factors were mentioned most at first glance, qualitative analysis revealed that internal factors were important and could not be well identified. Even if some entrepreneurs are aware of their own internal shortcomings, problems such as lack of strategy and vision, low level of education and insufficient social capital are not fully recognized. There is a strong attribution error between the reasons that entrepreneurs think fail to start a business and the actual reasons [36]. In addition, Cardon et al. (1999) argues that the entrepreneur's attributional style -- Helpless orientation and Mastery Orientation affect his or her attribution of failure. Helpless oriented refers to the tendency of individuals to explain negative events in terms of fairly stable and ordinary factors in themselves (e.g., I am a loser). This type of entrepreneur tends to blame failure on lack of ability. Mastery orientation refers to the tendency of individuals to explain negative events by temporary, specific factors outside of themselves (e.g., this is pure bad luck). This type of entrepreneur tends to attribute failure to lack of effort [37]. The empirical study of Eggers \& Song (2015) found that serial entrepreneurs attributed their previous failures to external factors due to self-serving bias, and thus changed the industries they entered in the subsequent entrepreneurship. However, this change invalidates their previous experience and is not conducive to the growth of current enterprise performance [39].

However, some scholars believe that although attribution may play an important role in the explanation of failure in the general organizational environment, the attribution literature fails to grasp the particularity of the entrepreneurial environment.

Even if the attribution is driven by psychological reasons, the narrators and audiences' explanations of failure reflecting the specific social environment are complex [13]. Some scholars begin to examine the causes of failure by using the narrative attribution of organizational stakeholders. Zacharakis et al. (1999) found that entrepreneurs and venture capitalists all produce attribution errors. Entrepreneurs and venture investors both think that internal factors are the main cause of others' entrepreneurial failure [33]. In addition, Mantere et al. (2013) think that entrepreneurial failure is a kind of complex social sensemaking, and the founders, business executives, employees and media make sense failure differently. They extracted the failure attributions from the descriptions of the failure causes of the three new media companies, namely narratives, and classified these attributions, and finally identified the key narrative attributions used to perceive failure [13]. The study found that only the founders attributed the failure to personal responsibility, while hired managers generally attributed the failure to others. Cardon et al. (2011) compared the differences in the public's attribution 
of entrepreneurial failure in different regions of the United States, and found that the public's perception of the causes of failure was different in different regions. Regardless of the entrepreneur's own attribution to the failure, in regions where the punishment for failure is more severe, the public often blames the failure on the entrepreneur himself and severely penalizes failure [38].

In general, the traditional research on entrepreneurial failure: concept definition, occurrence characteristics, and cause are still controversial -- the definition of entrepreneurial failure is difficult to reach consensus, and the data of entrepreneurial failure is unavailable to scholars. Quantitative research on the causes of entrepreneurial failure has not yet been able to establish a consensus on how and why enterprises fail [43]. Although some studies have begun to use attribution theory to explore the causes of failure, the complexity and uncertainty of individuals and their environment, as well as the occurrence of attribution errors, pose challenges to their persuasiveness. Therefore, more empirical studies are needed to further improve and supplement relevant concepts and build more mature and dynamic analytical models. The attribution theory applied in the previous literature and its implications are shown in table 1:

Table 1. Attribution theory applied in previous literature and its implications.

\begin{tabular}{ll}
\hline Attribution theory & implication \\
\hline \multirow{2}{*}{ fundamental attribution } & When attributing human behavior, people tend to overestimate the intrinsic tendency and ignore the situational factors. \\
actor-observer attribution & The phenomenon where personal attributions are greater than situational attributions. \\
self-serving & $\begin{array}{l}\text { Attributions to oneself as an actor and to others as an observer. } \\
\text { outcomes (such as failure) to environmental factors. }\end{array}$ \\
\hline
\end{tabular}

As shown in Table 1, the existing attribution theories used in entrepreneurial failure studies mainly include fundamental attribution, actor-observer attribution, and self-serving attribution. Some scholars use fundamental attribution to think that entrepreneurs who fail tend to overestimate their own mistakes in business failure when they reflect on failure, and are less likely to attribute the failure to situational factors. Other scholars believe that attributors as actors and observers differ in their attribution of failure. When it comes to the situation of business failure, the founder of a failed business and other external stakeholders or media have different interpretations of the reasons for failure [13]. In addition, some scholars analyzed the reasons for failure of entrepreneurs from the perspective of self-serving attribution [39]. Different interpretations of the causes of failure affect the degree of learning from failure and subsequent entrepreneurial behaviors after failure $[38,40]$.

\section{Consequences of Entrepreneurial Failure Attribution}

According to the existing research, the individual's attribution of failure affects the individual's intention to start a business again in both direct and indirect ways. Individuals who attribute their failures to factors beyond their control, such as the sluggish market environment and depression, may not start a business again, while those who attribute their failures to internal factors beyond their control, such as individuals without entrepreneurial ability, may not start a business again [40-42]. In addition, an individual's attribution of entrepreneurial failure influences subsequent entrepreneurial intention by influencing learning.

Individual attribution of failure will indirectly affect the performance of serial entrepreneurship [44, 45]. Different attributions may lead to different knowledge that individuals learn from failure $[45,46]$. Entrepreneurs who attribute failures to internal controllable factors tend to review their mistakes, think about how to do better next time, learn lessons from failures, update their management knowledge base, and thus promote the growth of subsequent startups [45]. On the contrary, those individuals who attribute their failures to external factors beyond their control may change industries in subsequent start-ups, which makes part of the knowledge they learn from failures ineffective [39], which is not conducive to the growth of serial entrepreneurship.

\section{Conclusion and Future Outlook}

By comparing the causes of entrepreneurial failure and the attribution theory in previous entrepreneurial failure literatures, we propose the following possible research directions in the future:

First of all, previous literature suggests that female entrepreneurs have a higher failure rate than male entrepreneurs [47]. However, few of these studies have continued to explore whether female entrepreneurs differ from male entrepreneurs in their attribution of failure, and whether attributions have different effects on their subsequent entrepreneurship and learning from failure. According to the attribution theory, due to the differences between men and women in expectation of success [48], people's perception of men and women [49], as well as the physical and mental structure and characteristics that actually exist between men and women, there are significant differences between men and women in attribution styles. Deaux and Emswiller (1974) examined attributions made by men and women about their success or failure in male or female tasks [50]. The results showed that no matter what kind of tasks, male subjects tended to attribute their good performance to internal factors such as their own skills and abilities, while when faced with failure results, they were unwilling to admit that it was their own skills, but attributed it to external factors such as the task. Female subjects' attribution was more dependent on the nature 
of the task: when they succeeded in the female task, they did not show a clear tendency to attribute it to their own characteristics, while when they failed in the female task, they tended to attribute it to their own skills. There were differences in male tasks. Both success and failure were attributed by female participants to external factors: success was attributed to good luck and failure to unfamiliarity with the task. This suggests that men tend to be more self-serving and self-protective in attribution than women. A person's gender role affects not only his own attributions about his behavior, but also others' attributions about his behavior.

To sum up, according to the attribution theory, there will be attribution differences between different genders. However, in the specific context of entrepreneurship, whether there is a difference in attribution of entrepreneurial failure between men and women remains unknown. Therefore, future research should use empirical research to discuss and test this issue.

Secondly, some literature on entrepreneurial failure suggests that the experience of entrepreneurs is a possible cause of entrepreneurial failure. Education is an important form of experience. According to attribution theory, if people think that they are very familiar with themselves and the situation, regardless of whether the information given by the outside world is consistent with their own judgment, such information tends to be underestimated or ignored, and people are more willing to believe in their own beliefs. According to this logic, the higher the level of education, the richer and more systematic the entrepreneur's knowledge will be, and the entrepreneur will be more confident in himself [5]. The more confident the entrepreneur is about himself, the more likely he is to attribute the failure to the outside rather than himself, no matter how others view the failure. However, existing studies have not explored and tested the relationship between educational level and attribution of failure from an empirical perspective.

Finally, the relationship between product types and attribution of entrepreneurial failure, namely the relationship between different task types and attribution of failure, has rarely been explored and verified. As mentioned above, women are more likely to engage in industries with a high failure rate, such as service or retail [24], which may be an explanation for the high failure rate of female entrepreneurs. According to this logic, the failure rate depends on different types of tasks, and entrepreneurs who run different types of tasks may also have different attributions for failure. Furthermore, different understandings of entrepreneurial failure attributions for different product types will also affect the industry fields and product types that entrepreneurs choose to enter in subsequent entrepreneurship [38]. The relationship between product types and attribution of entrepreneurial failure deserves further discussion in future studies.

In general, in the field of entrepreneurship, the application of attribution theory to the interpretation of the causes of entrepreneurial failure has become a hot research topic. The richness of attribution theory gives diversified perspectives to the interpretation of failure. This theory points out that the diversity of individual attributions in different situations is not only due to the complexity of individual perception and motivation, but also due to the diversity of tasks. On the basis of this theory, future studies should make an in-depth study of entrepreneurs' perceptions of failure and the impact of these perceptions on learning from failure and subsequent entrepreneurship.

\section{Acknowledgements}

This research is supported by "Research on Cultivation of Big Data Thinking and Application Ability of University Undergraduates: Based on the Perspective of Digital Economy" (GZJG20200203). This paper is grateful for the project "Research on the Government Procurement and Supply System for Sustainable Construction of the Rural Revitalization Demonstration Zone in Guizhou province".

\section{References}

[1] Cannon M D, Edmondson A C. Confronting failure: antecedents and consequences of shared beliefs about failure in organizational work groups [J]. Journal of Organizational Behavior, 2001, 22 (2): 161-177.

[2] Shepherd D A, Covin J G, Kuratko D F. Project failure from corporate entrepreneurship: Managing the grief process $[\mathrm{J}]$. Journal of Business Venturing, 2009, 24 (6): 588-600.

[3] Shepherd D A. Grief recovery from the loss of a family business: A multi- and meso-level theory [J]. Journal of Business Venturing, 2009, 24 (1): 81-97.

[4] Cannon M D, Edmondson A C. Failing to learn and learning to fail (intelligently): how great organizations put failure to work to innovate and improve [J]. Long Range Planning, 2005, 38 (3): 299-319.

[5] Ucbasaran D, Westhead P, Wright M. The extent and nature of opportunity identification by experienced entrepreneurs [J]. Journal of Business Venturing, 2009, 24 (2): 99-115.

[6] Ucbasaran D, Westhead P, Wright M, et al. The nature of entrepreneurial experience, business failure and comparative optimism [J]. Journal of Business Venturing, 2010, 25 (6): 541-555.

[7] McGrath R G. Falling forward: Real options reasoning and entrepreneurial failure $[\mathrm{J}]$. Academy of Management review, 1999, 24 (1): 13-30.

[8] Politis D, Gabrielsson J. Entrepreneurs' attitudes towards failure: An experiential learning approach [J]. International Journal of Entrepreneurial Behavior \& Research, 2009, 15 (4): 364-383.

[9] Shepherd D A. Learning from business failure: Propositions of grief recovery for the self-employed [J]. Academy of Management Review, 2003, 28 (2): 318-328.

[10] Liao J J, Welsch H, Moutray C. Start-Up resources and entrepreneurial discontinuance: The case of nascent entrepreneurs [J]. Journal of Small Business Strategy, 2008, 19 (2): $1-15$.

[11] Cope J. Entrepreneurial learning from failure: an interpretative phenomenological analysis [J]. Journal of Business Venturing, 2011, 26 (6): 604-623. 
[12] Ucbasaran D, Shepherd D A, Lockett A, Lyon S J. Life after business failure the process and consequences of business failure for entrepreneurs [J]. Journal of Management, 2013, 39 (1): $163-202$.

[13] Mantere S, Aula P, Schildt H, Vaara E. Narrative attributions of entrepreneurial failure [J]. Journal of Business Venturing, 2013 28: 459-473.

[14] Singh S, Corner P, Pavlovich K. Coping with entrepreneurial failure [J]. Journal of Management and Organization, 2007, 13: 331-344.

[15] Khelil N. The many faces of entrepreneurial failure: insights from an empirical taxonomy [J]. Journal of Business Venturing, 2016, 31 (1): 72-94.

[16] Headd B. Redefining business success: distinguishing between closure and failure [J]. Small Business Economics, 2003, 21 (1): 51-61.

[17] Stokes D, Blackburn R. Learning the hard way: the lessons of owner-managers who have closed their businesses [J]. Journal of Small Business and Enterprise Development, 2002, 9 (1): $17-27$.

[18] DeTienne D R, Mckelvie A, Chandler G N. Making sense of entrepreneurial exit strategies: a typology and test [J]. Journal of Business Venturing, 2015, 30 (2): 255-272.

[19] Alvarez S A, Busenitz L W. The entrepreneurship of resource-based theory [J]. Journal of Management, 2001, 27 (6): 755-775.

[20] Jenkins A, McKelvie A. Is this the end? investigating firm and individual level outcomes post-failure [J]. Journal of Business Venturing Insights, 2017, 8 : 138-143.

[21] Gelder J L V, Vries R E D, Frese M, et al. Differences in psychological strategies of failed and operational business owners in the Fiji Islands [J]. Journal of Small Business Management, 2010, 45 (3): 388-400.

[22] Hayward M L, Shepherd D A, Griffin D. A hubris theory of entrepreneurship [J]. Management Science, 2006, 52 (2): 160-172.

[23] Ucbasaran D, Westhead P, Wright M. Habitual Entrepreneurs Experiencing Failure: Overconfidence and the Motivation to Try Again [J]. Advances in Entrepreneurship Firm Emergence \& Growth, 2006, 9 (06): 9-28.

[24] Watson J. Failure rates for female-controlled businesses: Are they any different? [J]. Journal of Small Business Management, 2003, 41 (3): 262-277.

[25] Chrisman J J , Gatewood E , Donlevy L B. A Note on the efficiency and effectiveness of outsider assistance programs in rural versus non-rural states [J]. Entrepreneurship Theory and Practice, 2002, 26 (3): 67-80.

[26] Bruno A V, Leidecker J K. Causes of new venture failure: 1960s vs. 1980s [J]. Business Horizons, 1988, 31 (6): 51-56.

[27] Robinson S. Business failure rates: A look at sex and location [J]. Academy of Entrepreneurship Journal, 2007, 13 (1): 45-56.

[28] Carter S, Wilton W. Don't blame the entrepreneur, blame government: The centrality of the government in enterprise development; lessons from enterprise failure in Zimbabwe [J]. Journal of Enterprising Culture, 2006, 14 (1): 65-84.
[29] Aldrich H E, Fiol C M. Fools rush in? the institutional context of industry creation [J]. Academy of Management Review, 1994, 19 (4): 645-670.

[30] DiPietro W, Sawhney B. Business failures, managerial competence, and macroeconomic variables [J]. American Journal of Small Business, 1977, 2 (2): 4-15.

[31] Theng L G, Boon J L W. An exploratory study of factors affecting the failure of local small and medium enterprises [J]. Asia Pacific Journal of Management, 1996, 13 (2): 47-61.

[32] Venkataraman S, Van De Ven A H, Buckeye J, Hudson R. Starting up in a turbulent environment: A process model of failure among firms with high customer dependence [J]. Journal of Business Venturing, 1990, 5 (5): 277-295.

[33] Zacharakis A L, Meyer G D, DeCastro J. Differing perceptions of new venture failure: A matched exploratory study of venture capitalists and entrepreneurs [J]. Journal of Small Business Management, 1999, 37 (3): 1-15.

[34] Heider F. (1958). The psychology of interpersonal relations. New York: Wiley.

[35] Parker P, Arthur M B, Inkson K. Career communities: a preliminary exploration of member-defined career support structures [J]. Journal of Organizational Behavior, 2004, 25 (4): 489-514.

[36] Franco M, Haase H. Failure factors in small and medium-sized enterprises: qualitative study from an attributional perspective [J]. International Entrepreneurship \& Management Journal, 2010, 6 (4): 503-521.

[37] Cardon M, McGrath R G. When the going gets tough... : Toward a psychology of entrepreneurial failure and re-motivation [C]. Paper presented at the Frontiers of Entrepreneurship Research Conference, Babson College, Wellesley, MA, 1999.

[38] Cardon M S, Stevens C E, Potter D R. Misfortunes or mistakes? Cultural sensemaking of entrepreneurial failure [J]. Journal of Business Venturing, 2011, 26 (1): 79-92.

[39] Eggers J P, Song L. Dealing with Failure: Serial Entrepreneurs and the Costs of Changing Industries Between Ventures [J]. Academy of Management Journal, 2015, 58 (6): 1785-1803.

[40] Mandl C, Berger E S C, Kuckertz A. Do you plead guilty? Exploring entrepreneurs' sensemaking-behavior link after business failure $[\mathrm{J}]$. Journal of Business Venturing Insights, 2016, 5: 9-13.

[41] Weiner B. An attributional theory of achievement motivation and emotion. Psychology Review, 1985, 92: 548-573.

[42] Wolfe M T, Shepherd D A. "Bouncing back" from a loss: Entrepreneurial orientation, emotions, and ffailure narratives [J]. Entrepreneurship Theory \& Practice, 2015, 39 (3): 675-700.

[43] McKenzie B, Sud M. A hermeneutical approach to understanding entrepreneurial failure $[\mathrm{J}]$. Academy of Entrepreneurship Journal, 2008, 14 (2): 123-148.

[44] Yamakawa Y, Peng M W, Deeds D L. How does experience of precious entrepreneurial failure impact future entrepreneurship [J]. Academy of Management Meeting. 2010.

[45] Yamakawa Y, Peng M W, Deeds D L. Rising from the ashes: cognitive determinants of venture growth after entrepreneurial failure [J]. Entrepreneurship Theory and Practice, 2015, 39 (2): 209-236. 
[46] Yamakawa Y, Cardon M S. Causal ascriptions and perceived learning from entrepreneurial failure [J]. Small Business Economics, 2015, 44 (4): 797-820.

[47] Justo R,, DeTienne D R, Sieger P. Failure or voluntary exit? Reassessing the female underperformance hypothesis [J]. Journal of Business Venturing, 2015, 30 (6): 775-792.

[48] Feather N T, Simon J G. Reactions to male and female success and failure in sex-linked occupations: Impressions of personality, causal attribution, and perceived likelihood of difference consequences [J]. Journal of Personality and Social Psychology, 1975, 31: 20-31.

[49] McClelland, D. C.. Power: The inner experience. New York: McGraw-Hill, 1975.

[50] Deaux K, Emswiller T. Explanation of successful performance on sex-linked tasks: What is skill for the male is luck for female. Journal of Personality and Social Psychology, 1974, 29: 80-85. 